\title{
ESTUDIOS
}

\section{Borges, una Poética de la Desposesión}

1.

Uno de los tempranos y más inteligentes críticos de Borges señalaba que Lana die enfrente (1925) era "la obra maestra del ultraísmo en la Argentina". Claro que Néstor Ibarra - no era otro ese crítico- ${ }^{1}$ no quería con ello exaltar un valor absoluto en Borges; por el contrario, tendía a formular más bien un reparo, sólo que este reparo implicaba, paradójicamente, un reconocimiento también. El ultraísmo para Ibarra (hoy - y quizá aun entonces - no sólo para él) era casi insignificante como movimiento poético; el hecho de que Borges fuera su más alto exponente era proponer sobre todo que su obra trascendía los esquemas de la escuela - aunque no concebidos originalmente así, esquemas que, por cierto, el propio Borges había establecido y difundido. Así, tendríamos a un Borges maestro del ultraísmo pero justamente por lo que había en él de anti-ultraísmo; un maestro ligeramente herético en verdad. Esta paradoja (bastante cómica por lo demás), ¿no definía ya el carácter mismo de la obra borgiana? Casi se podría sacar como con. clusión esta alternativa: o Borges era todo el ultraísmo argentino, o no lo era para nada en lo que se supone característico de esa escuela. La diferencia siguiente, que ya señalaba el propio Ibarra, no deja de ser radical: a diferencia de los demás ultraístas, cuyas metáforas no poseían sino por azar algún valor emocional, "y frecuentemente sobre todo la rebuscada incoherencia y el gratuito mal gusto, la imagen de Borges nunca es sino tentativa de expresión, se supedita siempre a la necesidad de una comunicación".

Pero no vamos, por supuesto, a iniciar o reiniciar un debate sobre el tópico de las escuelas literarias, esos "conventículos y sectas / que las crédulas universidades veneran", dice hoy burlonamente Borges. ${ }^{2}$ Ese de.

1 La mueva poesía argentina (ensayo crítico sobre el ultraísmo, 1921-1929). Buenos Aires, 1930.

? Elogio de la sombra. Buenos Aires, Emecé, 1969. 
bate no tendria sentido, menos ahora que nunca cuando todos en Latinoamérica parece que somos más o menos barrocos o surrealistas, o las dos cosas a la vez. Es sabido cómo Borges ha hablado luego del ultraísmo como la equivocada secta de los áridos poemas, y aun en su época de relativo auge cómo empezó a dudar de su eficacia. Tres años después de la aparición de Luna de enfrente, escribía en un ensayo sobre la imagen: "La más lisonjeada equivocación de nuestra poesía es la de suponer que la invención de ocurrencias y de metáforas es tarea fundamental del poeta y que por ellas debe medirse su valimiento. Desde luego confieso mi culpabilidad en la difusión de ese error". " En su último libro de poemas (El elogio de la sombra, 1969), en un texto en que habla irónicamente de la "vanguardia", incluso el u'traísmo deja de existir como tal. "Fuimos el imagismo, el cubismo", dice, como resumiendo las tentativas de su generación (y esta vez no sólo argentina). Al hablar del "imagismo" quizá Borges no busca tanto revivir una secta (o una escuela) como situarse dentro de una visión más universal del arte contemporáneo. Fero es cierto también que ante ese nombre el lector podrá pensar en el movimiento del "Imagism", que inició Ezra Pound en la poesía de lengua ing!esa hacia 1912. Y, en verdad, hay relaciones evidentes entre el pensamicnto de Borges y ese movimiento. Indiquemos brevemente algunas: la busca de la palabra justa y la abolición de todo adorno (como los adjetivos haraganes, diría Borges), la claridad del desarrollo, la presentación directa de la "cosa" ya objetiva o subjetiva, la concentración y el rechazo de la vaguedad (principios nada nuevos, decían los imagistas; sólo que habían caído en desuso, empobreciendo la naturaleza misma de la poesía). Habría que poner de relieve, además, una quizá más central: la imagen. "An Image is that which presents an intellectual and emotional complex in an instant of time", la definía Pound, trascendiendo los límites puramente visuales o sensoriales de la concepción tradicional. El Borges de los años veinte decía a'go parecido: igualmente rechazaba la imagen como mera decoración sensorial, así como la aparente audacia inventiva que cra más bien confusión. "El deber de toda imagen es precisión", argumentaba. La imagen había de scr, además, una visión más profunda y esencial del mundo, que exprese "los momentos de alguna intensidad de pasión"."

3 El idioma de los argentinos. Buenos Aires, M. Gleizer Editor, 1928. El errot nunca arredra a Borges; el personaje de uno de sus relatos confiesa: "para estar libre de un error, conviene haberlo practicado" (El Aleph).

* Literday Essals of Ezra Pound. New York, New Directions, 1968.

5 El idioma, ob. cit. 
2.

Pero más reveladoras que las teorías son los poemas. La poesía de Borges, desde sus comienzos, se presenta en gran medida como una rereflexión sobre el mundo y sobre la poesía misma ("mi verso es de interrogación y de prueba / y para obedecer lo entrevisto", dice en un poema). Ya en Fervor de Buenos Aires (1923) esa reflexión se manifiesta como duda frente al lenguaje, o más bien: la resistencia del mundo a dejarse aprehender por las palabras, crea esa duda. "La ciudad está en mí como un poema / que no he logrado detener en palabras", afirma en un poema de ese libro ("Vanilocuencia"). En ese mismo poema, en que se habla del ámbito de la ciudad, de sus calles y sus casas, Borges finalmente se pregunta por el sentido del escribir: puesto que la realidad está en continuo cambio, Ia palabra nunca podrá fijarla; la realidad, agrega, desdeña "los símbolos verbales":6 Esa duda reflexiva (o reflexión dubitativa) se corresponde, a su vez, simultáneamente, con la visión que del vacío del mundo y del hombre mismo tiene Borges. En poemas de ese mismo libro, habla de "nuestra esencial nadería"7 y se refiere a las cosas como "ajenas de sustancia". De esta última evidencia surgirá, por contraste, atro impulso en Borges: el mundo es actividad del alma, hay que intentar fundarlo, sostenerlo o restablecerlo con la palabra. No sólo ello: hay que penetrar más entrañablemente en las cosas a través de un lengua. je que descubra en ellas lo realmente vivo, su sucesivo discurrir y también su eternidad. "Suele suponerse - escribe-- que la literatura ha dicho las palabras esenciales de nuestro vivir y sólo puede innovar en las gramatiquerías y en las metáforas. Me atrevo asegurar lo contrario: sobran laboriosidades y faltan presentaciones válidas de lo eterno: de la felicidad, de la muerte, de la amistad".8 De ahí que su lenguaje asuma la forma de la pasión (de la pasión, no del sentimentalismo), que en Borges abarca espontáneamente la inteligencia y el fervor. Ese lenguaje es, también, una continua vivencia del mundo, su trato cotidiano, su asimilación.

G Curiosamente, Borges elimina este poema en una nueva edición, muy corregida, de Fervor de Buenos Aires (Buenos Aires Emecé, 1969). Pero el tema sigue siendo una de las perspectivas radicales de su obra de la madurez: la busca de la palabra esencial que encarne y descifre al universo, que Borges dsarrolla con mayor ironía; v.g. "Parábola del Palacio", "El otro tigre".

7 El poema es "Calle desconocida" y el pasaje dice así: "y la venida de la noche se advierte / como una música esperada, / no como simbolo de nuestra esencial naderia". En la nueva versión de FBA (cf. nota $n^{\circ}$ 6), el último verso es suprí. mido, mientras se prolonga el símil iniciado en el segundo: "como una música esperada y antigua, / como un grato declive". Es decir, Borges pone énfasis sólo en la noche, que, en sus últimos poemas (Elogio de la sombia) es más bien un símbolo de serenidad y aun de encuentro con sụ cifra secreta.

$\$$ El idioma, ob. cit: 
"Las cosas no son intrínsecamente poéticas —anotaba también; para ascenderlas a poesía, es preciso que las vinculemos a nuestro vivir, que nos acostumbraremos a pensarlas con devoción". ${ }^{9}$ El poeta debe estar alerta a "ese diálogo de alusiones / que toda agrupación humana va urdiendo"; así, de alguna manera el mundo se le tornará más dócil: v.g. la verja de un jardín se abrirá como la página "que una frecuente devoción interroga". La busca del Borges de esta época podría resumirse en este propósito: ser admitido "como parte de una Realidad innegable, / como las piedras y los árboles ("Llaneza"). Esa aspiración es, por supuesto, la busca de una plenitud y de un absoluto a partir justamente de su carencia.

Pero la plenitud en Borges tiene un especial contexto. No es la expansión hacia el mundo, ni la conquista de su diversidad (sabemos que para Borges la excesiva presencia es caos y éste, a su vez, irrealiza las cosas); por el contrario, es una suerte de reducción; busca asentarse "en las dos cosas primordiales que existen: en la tierra y en el cielo" ("Cercanías", FBA). Y aunque en varios poemas de Luna de enfrente parece asumirla como justificación de sí mismo y de su poesía ("En mi secreto conrazón yo me justifico y ensalzo"), vemos que esa justificación trasciende lo individual; por ello, añade: "He atestiguado el mundo; he confesado la rareza del mundo", "He dicho asombro de vivir, donde otros dicen / solamente costumbre" ("Casi juicio final"). Así, en otros poemas de ese libro la plenitud es un destino secreto, la aceptación de un límite y la fidelidad al universo que es también su universo. Después de evocar todo lo que ha sido su vida (la dicha y el pesar, los viajes, el mar, las tierras conocidas, el amor, los arrabales infinitos, las palabras), asegura finalmente: "Creo profundamente que eso es todo y que ni veré / ni ejecutaré cosas nuevas" ("Mi vida entera"). El poema, creo, lejos de expresar una satisfacción, lo que propone más bien es un limite: a partir del cual puede iniciarse la verdadera aventura de ahondamiento en el universo. Pero, además, la evocación misma que se hace en ese poema no puede ser mayor indicio de pobreza; lo cual no es nada raro: la plenitud en Borges se confunde íntimamente con ella. "El mar es una espada innumerable y una plenitud de pobreza", escribe en otro poema ("Singladura"). Y en el prólogo de Luna de enfrentie, definiendo a este libro, se refiere con frecuencia a esa pobreza: "Este cartel de mi pobreza"; "es mi enterizo caudal pobre". Ello revela la sensibilidad profunda de Borges: su ironía, su reticencia.

9 Idem. 
Estamos, pues, ante una plenitud que es más una ética y una utopía que una pura posesión; vive alternativamente del descreimiento y de la fe (como la poesía que ella origina); en todo caso, es menos una afirmación del yo que del universo. Pero es lo que ahora intentamos esclarecer, de manera concreta, en el poema que hemos escogido para comen. tar un poco más ampliamente.

3.

Ese poema es "Jactancia de quietud", quizá la verdadera poética del Borges de la primera época, es decir, hasta 1930. Como casi todos los poemas de Lunu de enfrente, al que pertenece, Borges adopta en él el versículo y un tono sentencioso; ese tono excluye la vaguedad, no la riqueza alusiva, y lo conceptual: el pensamiento sabe encontrar a través de imágenes concretas (elementos del mundo habitual de Borges) su intensidad emotiva. Se desarrolla en totno a una oposición central: un yo enfrentado a los otros. Esa oposición asume tanto una implicación estética como espiritual o ética; estética: formula una crítica a toda elocuencia desmesurada (y no sólo expresiva) así como a la falsa novedad; ética: propone una suerte de ascetismo, de despojamiento, que, sin embargo, es el camino hacia otra plenitud. Pero, a su vez, esa oposición origina otras: la quictud frente al movimiento, la lucidez frente a la pura ambición, la secreta intimidad frente a todo énfasis. Así, la aparente afirmación inicial del yo se va resolviendo no en su exaltación absoluta, sino en su contrario: la despersonalización y, a través de ésta, en una presencia más vasta, la del universo. De ahí el título, que no deja de ser sorpresivo: jactoncia de lo que, dentro de una tradicional conciencia valorativa, parecería no merecerlo: la inmovilidad, la ausencia. El título, pues, sugiere ya el espíritu del poema: la paradoja, es decir, la afirmación de algo por medio de su negación. En la versión que aparece en Obra poética (1967), el poema dice así:10

10 De la versión original (de 1925) se corrigen los versos siguientes: v.4́: como un lazo"; v.5: "tregua de la ira en la espada"; v.9: "Mi patria es un reclamo de guitarra, una promesa en oscuros ojos de niña, / la oración manifiesta del sauzal..." Es casi obvio decir que la rersión que comentamos mejora el original. Sustituir el segundo término de la enumeración en el v.9 por "unos retratos y una vieja espada", le comunica al verso un tono más simbólico sin dejar de ser personal; esa "vieja espada", además, evoca ya los poemas de alguna manera épicos que Borges escribirá después a sus antepasados. Este añadido, por lo demás, tuvo otro efecto benéfico: lleva a reemplazar "la espada" del v.5 por "el hierro", que da a ese verso su verdadera connotación negativa. En la más reciente edición de Luna de enfrente (conjuntamente con Cuadernos San Martin; 


\section{JACTANCIA DE QUIETUD}

1. Escrituras de luz embisten la sombra, más prodigiosas que meteoros.

2. La alta ciudad inconocible arrecia sobre el campo.

3. Seguro de mi vida y de mi muerte, miro los ambiciosos y quisiera entenderlos.

4. Su día es ávido como el lazo en el aire.

5. Su noche es tregua de la ira en el hierro, pronto en acometer.

6. Hablan de humanidad.

7. Mi humanidad está en sentir que somos voces de una misma penuria.

8. Hablan de patria.

9. Mi patria es un latido de guitarra, unos retratos y una vieja espada,

10. la oración evidente del sauzal en los atardeceres.

11. El tiempo está viviéndome.

12. Más silencioso que mi sombra, cruzo el tropel de su levantada codicia.

13. Ellos son imprescindibles, únicos, merecedores del mañana. Mi nombre es alguien y cualquiera.

14. Su verso es un requerimiento de ajena admiración.

15. Yo solicito de mi verso que no me contradiga, y es mucho.

16. Que no sea persistencia de hermosura, pero sí de certeza espiritual.

17. Yo solicito de $\mathrm{mi}$ verso que los caminos y la soledad lo atestigüen.

18. Gustosamente ociosa la fe, paso bordeando $\mathrm{mi}$ vivir.

Buenos Aires, Emecé, 1969), quedan eliminados los cinco versos que siguen a "Mi nombre es alguien y cualquiera", y éste es destacado como un verso aparte. Esta supresión, me parece, debilita al poema an cuanto "arte poética" explícita; queda, así, como una ética, pero ésta misma tiene implicaciones estéticas. Un estudio de las sucesivas correcciones que Borges ha practicado en su poesía, queda por hacer; sin duda sería revelador para comprender su estilo. Muchos de esas correcciones, sin embargo, son verdaderos desaciertos. Un ejemplo: en el poema "Final de año" (FBA), "la sospecha universal y borrosa / del enigma del Tiempo" es corregido de una manera excesivamente conceptual: "la sospecha universal y borrosa / de que a despecho de que somos / las gotas del río de Heráclito", en la nueva edición de FBA (cf. nota no 6 ). 
19. Paso con lentitud, como quien viene de tan lejos que no espera llegar.

Ya los dos versos iniciales insinúan, de manera un tanto elíptica esta vez, las sucesivas oposiciones que integran el poema. En efecto, tienden a sugerir el contraste entre el vértigo de la ciudad y la quietud del campo. El primer verso aparece como una imagen visual sin inmediata referencia (escoger como imagen sugerida la palabra "escrituras" va a trascender lo visual), que luego es esclarecida en el segundo: esas luces "más prodigiosas que meteoros" son la ciudad cosmopolita (de "calles enérgicas / molestadas de prisas y ajetreos", como la llama Borges en el primer poema de Fervor), ajena al otro Buenos Aires que es el que Borges realmente ama: la ciudad de los arrabales, un tanto ya anacrónica. En estos dos versos, pues, se destaca el movimiento: las luces son "meteoros" y. "embisten" a Ia sombra, la ciudad "arrecia" sobre el cam. po. Fero ese movimiento no es sólo externo; va a tomar una connotación espiritual a lo largo del poema: de alguna manera es la profanación de un orden secreto (la sombra; "más silencioso que mi sombra", se dice luego en el v. 11) y también de un orden mitológico (el campo, la pampa) que Borges busca preservar. Es, igualmente, el símbolo de los otros. De ahí que los versos siguientes (3.5) se defina a éstos a través de pasiones imperiosas: la ambición que se vuelve avidez, ira (y codicia, se dice en el v.11). Aparentemente, las imágenes con que se presenta a esas pasiones son épicas; en verdad, proponen un sentido menos (o nada) noble: la ferocidad de los que siempre ("su dia", "su noche") están acechando al mundo para "acometer", para imponerse. Pero de estos tres versos ya el primero nos muestra el verdadero rostro de Borges ("Seguro de mi vida y de mi muerte, miro los / ambiciosos y quisiera entenderlos"); es el rostro de un ser a la vez perplejo y decidido, que asume su destino más radical, algo en que se está sin equívoco y que los otros, sin embargo, eluden para conquistar una apariencia que es sólo vanidad. Se trata, de alguna manera, de la oposición entre el "conquistador" y el "asceta"; quizá también entre lo histórico (que estimula toda voluntad hacia el poder) y lo anacrónico (que postula su renunciamiento).

A partir del verso sexto, el poema va a girar en torno a la oposición de estas dos actitudes. El séptimo no sólo viene a reiterar lo que es la naturaleza esencial del hombre, sino que propone el desamparo como la única forma de ser. Así, mientras los otros hablan casi en abstracto de "humanidad", Borges siente, con desgarramiento existencial, que su única 
humanidad es "que somos voces de una misma penuria". La penuria es la de ser para la muerte, pero ese es el destino al que el hombre debe enfrentarse: todo movimiento de la historia sería puio enajenamiento si no se cobra conciencia de ese centro fijo y fatal. Borges no rechaza la historia: quiere trascenderla como fuerza abstracta y ciega, que en el fondo sería el verdadero vacio. De manera significativa los otros hablan de "humanidad" o de "patria" sin ninguna connotación que matice, individualice o comunique una vida concreta. Significativo, repito; sugiere que esas palabras son meros conceptos para ellos, y su aparente universalidad es una inconfesable indigencia. Son simplemente una retórica (los adjetivos que faltan el lector los podría suplir indiscriminadamente; se les supone) que lo justifica todo, pero no verdaderas realidades en las que se está y que uno justifica desde adentro de ellas mismas.

A esa abstracción, Borges opone siempre la individualidad. "El tiem. po está viviéndome", dice (v.10). El laconismo de la frase y el uso del verbo "estar" sugiere no sólo lo personal ("única y personal como un recuerdo", dice de la muerte en un poema de FBA), sino también la perplejidad y la intensidad ante la experiencia del tiempo. Esa experiencia, sabemos, es una de las más radicales en Borges: nuestro destino no es espantoso por irreal - dirá en uno de sus ensayos--, ${ }^{11}$ sino porque es irreversible y de hierro. Por otra parte, su "patria" (v.9) es también y sobre todo, una vivencia, una suerte de devoción de la memoria, algo infinitamente menos visib'e y ostentoso: "el latido de una guitarra", "unos retratos y una vieja espada", "la oración evidente del sauzal en los atardeceres". Podría pensarse que Borges está exaltando aquí una nueva especie de localismo histórico o, más aún, de criollismo estético. "La excesiva insistencia en su especialísimo criollismo", le reprochaba Néstor Ibarra. Cierto o no (ante Borges todo parece relativo), subrayemos el calificativo "especialísimo". En verdad, lo es. Lo que Borges busca no es lo pintoresco, sino lo marginal (no hay que repetir que los arrabales, las casas antiguas, los patios, las tapias y toda la mitología porteña son los elementos que constituyen su Buenos Aires). Y lo marginal tiene una implicación simbólica en él ("Yo presentí la entraña de la voz las orillas", dice no sin cierta clarividencia, en el último poema de LE). Es una de las maneras de oponerse al tiempo, dándole fuerza a lo anacrónico, convirtiendo lo efímero en una vasta memoria personal. Pero es sobre todo, creo, una experiencia o una prueba espiritual: despojamiento de "la prolijidad de lo real", que correspondería a un despojamiento interior; búsqueda, igualmente, del centro. Así, uno

11 Otras inquisiciones. Buenos Aires, Emecé, 1952. 
de los ragos más singulares de la obra de Borges consiste en insertar la preocupación metafísica dentro de lo más cotidiano y en apariencia insig. nificante. Son múltples los ejemplos; escojamos uno de los años iniciales: en un poema de Fervor, el tema de la guitarra se transforma en una visión más amplia: la infinitud de la pampa. En ese poema, aún dentro de su sencillez e ingenuidad, está ya implícita la experiencia (y hasta cierta técnica enumerativa a través del verbo "ver" de "El Aleph"). En uno de sus ensayos, Borges la resumiría así: "el menor de los hechos presupone el inconcebible universo e, inversamente, el universo necesita del menor de los hechos". ${ }^{12}$ Esa experiencia supone, apenas hay que decirlo, una concepción panteísta del mundo, que Borges ya expresa en uno de los versos más memorables del poema que analizamos: "Mi nom. bre es alguien y cualquiera". En efecto, en él ya está resumido todo el Borges posterior: su idea de que un hombre es todos los hombres y ninguno, un autor todos los autores; la despersonalización como la manera más auténtica de ser. Dentro del poema, además, esa frase tiene un específico sentido crítico ante los que hacen de la poesía un desmesurado ejercicio del yo y de su vanidad. Esos "imprescindibles, únicos, merecedores del mañana" (v.12), ¿no anuncian, en cierta medida, al desafo. rado Carlos Argentino Daneri (de "El Aleph"), que pretendía escribir el poema de nuestro planeta?

Así, después de poner en cuestión la autenticidad de la poesía de los codiciosos y hasta de toda una baja moral de cierto arte contemporáneo ("Su verso es requerimiento de ajena admiración"), es cuando Borges empieza a definir (v. 14.17) su propia poesía. Toda la ética implícita en los versos anteriores adquiere ahora su concreta significación estética: Pero lo que define Borges, en verdad, es más una búsqueda y un proceso espiritual que el resultado de una obra. De manera significativa, lo que él "solicita" no es una justificación puramente estética de su poesía; no busca que ésta sea "persistencia de hermosura, pero sí de certeza espiritual". Esa certeza, sin embargo, no será sólo de orden individual, aunque la fidelidad con la propia visión de Borges sea un primer requerimiento ("que no me contradiga, y es mucho", dice); ha de ser, igualmente, una fidelidad con el mundo: "Ios caminos y la soledad" deben atestiguarla. ¿No estamos ante otra de las paradojas borgianas? Si y no. Borges no intenta formular ningún realismo "terre à terre", sino una ética de la creación, que, a su vez se constituye en una estética más amplia: la visión del universo. Si leemos bien en la última imagen (v.16), lo que ella parece sugerir es que la poesía se define sobre todo por ser acto $\mathrm{y}$

12 Discusión. Buenos Aires, Emecé, 1957. 
búsqueda ("caminos"), a la vez que ese acto es una aventura sin respuestas dadas ni previstas, una "soledad" en la que, sin embargo; se debate su verdadera autenticidad. Por ello, el verso siguiente (v.17) no es una simple declaración de fe: ésta prefiere ser "ociosa", vacante, por. que de alguna manera intuye que su destino es la no posesión y, más bien, el continuo anhelo como única realidad. El poeta, así, pasa por su vida de manera lateral, bordeándola. De igual modo, el verso último no será la conclusión de esa aventura, sino su incesante prolongación. Quien la emprende "viene de tan lejos que no espera llegar". Es, pues, un regreso que es igualmente un punto de partida. El poema, en fin, como toda la obra borgiana, no tiene final, ni lo propone. Nueva paradoja: un poema que es una jactancia de quietud lo que sugiere en última instancia es el movimiento, la búsqueda, casi infinita, de algo que nunca podrá ser alcanzado.

Es evidente: la quietud nos remite a toda una visión simbólica de Borges. Vale la pena, entonces, preguntarse cuáles son sus implicaciones. En varios poemas de Fervor podríamos encontrar algunos indicios. Contemplando uno de los cementerios de Buenos Aires (en una suerte de regreso a su Hades familiar), Borges dice: "Nos place la quietud, / equivocamos tal paz de vida con el morir / y alabamos el sueño y la indiferencia" ("La Recoleta"). En otro poema, cuyo tema es el enigma del tiempo: su discurrir y la intuición (o la sospecha) de que algo más invulnerable se salva de ese discurrir, se dice finalmente: "es el asombro ante el milagro / de que a despecho de azares infinitos / perdure algo en nosotros: / inmóvil" ("Final de año"). Un poema de Luna de enfrente podría ser la reiteración de los anteriores, pero añade una visión más significativa. Es uno de los pocos poemas de amor en la obra de Borges ("Amorosa anticipación"); el amor no como posesión, sino, diríamos, como revelación: el anhelo por encontrar el verdadero ser de la mujer, la otra orilla de su vida que, sin embargo, no está en ella misma. Sólo a través de la quietud podría divisar esa orilla, "esa playa última de (su) ser", dice Borges. En estos tres poemas, la quietud parece inicialmente identificarse con la muerte; en verdad, es un símbolo de otra vida (más plena porque es revelación de la totalidad) y de lo perdurable; es, además, una suerte de ataraxia (lo imperturbable ante el tiempo y el espacio) y de sueño del mundo. La quietud es, pues, una ausencia que, a su modo, es la Presencia; una desposesión que implica otra plenitud.

En uno de los ensayos de El idioma de los argentinos, encontramos la idea de esta extraña dialéctica. Hay una plenitud, dice Borges, que 
corresponde al nirvana, el cielo negativo de los budistas: ausencia total del yo, de la objetividad del tiempo y del espacio, del mundo. Esa ausencia, sin embargo, no es negatividad absoluta, sino sólo privación, y bastaría con invertir los signos para que la nada fuese también una realidad. $\mathrm{La}$ ausencia sería, pues, un camino hacia la plenitud y aun hacia lo absoluto. Imaginar que no ser es más que ser algo y, de alguna manera, serlo todo: esta aparente falacia (de la que él se hace cómplice) es lo que propone Borges en uno de sus ensayos de los años cincuenta. ${ }^{13}$ Ella es la que sustenta toda su obra. Veamos un ejemplo reciente. En un poema de Elogio de la sombra, Borges evoca la promesa de un pintor amigo de regalarle un cuadro; el amigo muere antes de cumplir su promesa. Y Borges afirma: "Sólo los dioses pueden prometer, porque son inmortales". Pero luego piensa que de haber tenido el cuadro, éste se habría convertido en una cosa más con el tiempo, habría sido, incluso, un objeto más, atado a las vanidades de la casa. La irrealizada promesa, en cambio, le otorga una presencia más intacta del cuadro: algo que es ahora ilimitado, incesante, "capaz de cualquier forma / y cualquier color y no atad(o) a ninguno". Borges concluye: "Gracias, Jorge Larco. / (También los hombres pueden prometer, porque en la promesa / hay algo inmortal)". Ese poema se titula The unending gift; lo que es ya significativo: la desposesión, la irrealidad y la ausencia son, para Borges, dones (revelan la verdadera presencia), pero dones incesantes (nunca cristalizados en una dimensión objetiva). Así encontramos otra de las claves de la dialéctica borgiana. Su obra opera no sólo a través de la inversión cle signos, sino también a través de su reversión: la posibilidad, que implica lo primero, de encontrar lo absoluto, se ve continuamente revertida a su imposibilidad; esto es, la presunción de lo absoluto se resuelve no en su posesión, sino en el distanciamiento y aún la renuncia de él. En otras palabras, la Presencia (así como el libro que sea el Libro que, a su vez, sea el Universo) es una utopía; Borges la busca y habla de ella desde su ausencia; esta ausencia es quietud, perpetuo móvil que, por ello mismo, remite a la inmovilidad. Esa quietud es también lo marginal, pero desde ella Borges habla de lo central.

Toda esta dialéctica, creo, es lo que ya encontramos implícito en el poema que hemos comentado. Este poema es de la primera época de Borges, pero, en verdad, la trasciende y parece prefigurar toda su obra posterior. En el libro suyo que al comienzo citamos, Ibarra afirmaba que en Borges no hay contextos. Hoy no podríamos decir lo mismo.

31 Otras inquisiciones, ob. cit. 
Como en su visión del universo, en la obra de Borges un poema o una frase puede remitirnos a la totalidad de esa obra. Y quizá uno de los valores de "Jactancia de quietud" sea el darnos una prueba de ello. ${ }^{14}$

GUILLERMO SUCRE

University of Pintsburgh

14 Las únicas abreviaturas empleadas en este artículo son: FBA (Feivior de Buenos Aires) y LE (Luna de enfrente). 